\title{
Apolipoprotein E expression is elevated by interleukin 1 and other interleukin 1 -induced factors
}

Ling Liu', Orwa Aboud ${ }^{1}$, Richard A Jones ${ }^{1}$, Robert E Mrak ${ }^{4}$, W Sue T Griffin ${ }^{1,2,3^{*}}$ and Steven W Barger ${ }^{1,2,3}$

\begin{abstract}
Background: We have previously outlined functional interactions, including feedback cycles, between several of the gene products implicated in the pathogenesis of Alzheimer's disease. A number of Alzheimer-related stressors induce neuronal expression of apolipoprotein $E(A p o E)$, $\beta$-amyloid precursor protein $(\beta A P P)$, and fragments of the latter such as amyloid $\beta$-peptide (AB) and secreted APP (SAPP). These stressors include interleukin-1 (IL-1)-mediated neuroinflammation and glutamate-mediated excitotoxicity. Such circumstances are especially powerful when they transpire in the context of an APOE \&4 allele.
\end{abstract}

Methods: Semi-quantitative immunofluorescence imaging was used to analyze rat brains implanted with IL-1 $\beta$ slow-release pellets, sham pellets, or no pellets. Primary neuronal or NT2 cell cultures were treated with IL-1 $\beta$, glutamate, A $\beta$, or sAPP; relative levels of ApoE mRNA and protein were measured by RT-PCR, QRT-PCR, and western immunoblot analysis. Cultures were also treated with inhibitors of multi-lineage kinases-in particular MAPK-p38 (SB203580), ERK (U0126), or JNK (SP600125)-prior to exposure of cultures to IL-1 $\beta, A \beta$, sAPP, or glutamate.

Results: Immunofluorescence of tissue sections from pellet-implanted rats showed that IL-1 $\beta$ induces expression of $\beta A P P, I L-1 \alpha$, and ApoE; the latter was confirmed by western blot analysis. These protein changes were mirrored by increases in their mRNAs, as well as in those encoding IL-1 $\beta, I L-1 \beta$-converting enzyme (ICE), and tumor necrosis factor (TNF). IL-1 $\beta$ also increased ApoE expression in neuronal cultures. It stimulated release of SAPP and glutamate in these cultures too, and both of these agents-as well as A $\beta$-stimulated ApoE expression themselves, suggesting that they may contribute to the effect of IL-1 $\beta$ on ApoE levels. Inhibitors of MAPK-p38, ERK, and JNK inhibited ApoE induction by all these agents except glutamate, which was sensitive only to inhibitors of ERK and JNK.

Conclusion: Conditions of glial activation and hyperexcitation can elevate proinflammatory cytokines, ApoE, glutamate, $\beta A P P$, and its secreted fragments. Because each of these factors promotes glial activation and neuronal hyperexcitation, these relationships have the potential to sustain self-propagating neurodegenerative cycles that could culminate in a progressive neurodegenerative disorder such as Alzheimer's disease.

Keywords: Alzheimer's disease (AD), amyloid beta (AB), apolipoprotein $E(A p o E)$, beta amyloid precursor protein

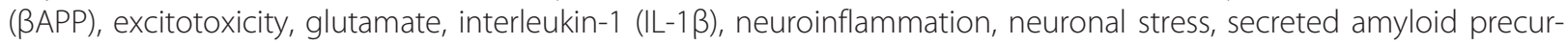
sor protein (SAPP)

\footnotetext{
* Correspondence: griffinsuet@uams.edu

'Department of Geriatrics, University of Arkansas for Medical Sciences, Little

Rock AR 72205, USA

Full list of author information is available at the end of the article
} 


\section{Introduction}

The pluripotent glial cytokine interleukin-1 (IL-1) and the CNS-abundant, lipid-cholesterol-carrying protein apolipoprotein $E$ (ApoE) are key participants in the pathogenesis of Alzheimer's disease (AD). ApoE contributes both to learning and to recovery from neural injury [1], perhaps by enhancing synaptogenesis by influencing Reelin signaling [2,3]. In humans, singlenucleotide polymorphisms in the coding region of the ApoE gene $(A P O E)$ yield three alleles $(\varepsilon 2, \varepsilon 3, \varepsilon 4)$ that translate into three distinct protein sequences, ApoE2, ApoE3, and ApoE4. Inheritance of the particular isoform of ApoE encoded by the $\varepsilon 4$ variant of the $A P O E$ gene confers significant risk for precocious development of $\mathrm{AD}[4,5]$ : those with two copies of the $\varepsilon 4$ allele of $A P O E$ have a $50-90 \%$ chance of developing AD by the age of 85 , and even one copy confers a three-fold increase in risk over individuals with no $\varepsilon 4$ alleles [6]. Though ApoE is primarily expressed in astrocytes in the healthy brain, stressors can induce its expression in neurons $[7,8]$.

Although not as strongly associated with AD risk as possession of ApoE4 sequences, specific polymorphisms in the genes encoding IL- $1 \alpha$ and IL- $1 \beta$ are also associated with increased AD risk. Specifically, variations in the promoter region of $I L 1 A$ and in the coding region of $I L 1 B$ influence AD risk when homozygous in one gene or heterozygous in both [9-13]. Glial activation marked by excess production of both IL- $1 \alpha$ and $\beta$ is a constant feature in several conditions associated with increased risk for precocious development of AD: $i$ ) traumatic brain injury (TBI) [14], ii) systemic viral disease, e.g., AIDS [15]; iii) the neuronal hyperexcitability of epilepsy [16-19]; iv) chromosome 21 anomalies such as Down's syndrome [20]; and $v$ ) advancing age [21-23]. Each of these stressors is associated with precocious development of $\mathrm{AD}[18,24,25]$, especially in those who have inherited one or more $\varepsilon 4$ alleles of APOE [1,26-29].

Excess production and secretion of IL- $1 \beta$ elevates neuronal expression of the precursors of each of the changes characteristic of AD. These neurodegenerationrelated precursors include $\beta$-amyloid precursor protein $(\beta \mathrm{APP})$, which may lead in vivo to deposition of $A \beta$ [30] and further induction of IL-1 $\beta$ [31]; ApoE, which is present in plaques [32] and necessary for the accumulation of $\mathrm{A} \beta$ deposits [33]; and hyperphosphorylated tau [5], the principal component of neurofibrillary tangles. IL-1 also induces $\alpha$-synuclein [34], the Lewy body precursor.

Despite the potential for contributing to the production of $A \beta$, elevations of $\beta$ APP may participate in compensatory responses. $\beta$ APP is elevated in response to stressors beyond IL-1 $\beta$, including excitotoxins and age itself, yet AD pathology is correlated with a deficiency in $\beta$ APP expression [35]. ApoE appears to mediate the compensatory induction of $\beta$ APP; blocking ApoE synthesis or its receptors inhibits the effect of glutamate on $\beta$ APP [35]. $\beta$ APP knockout mice show learning and memory deficits [36] and die prematurely [37]; secreted $\beta$ APP (sAPP) is generally neuroprotective [38]. Taken together, these findings suggest that possession of an $\varepsilon 4$ allele or ApoE insufficiency compromises neurological parameters and exacerbates injury-induced deficits at least in part by limiting inductions of $\beta$ APP. ApoE, especially ApoE3, may also serve to keep inflammatory reactions in check [39-41]. A possible mechanism is suggested by the ability of ApoE to suppress the proinflammatory activity of sAPP [31].

In $\mathrm{AD}$, activated microglia overexpressing IL-1 are present in diffuse $A \beta$ deposits prior to the appearance of ApoE [32]. With normal aging, the brain shows increased microglial activation and expression of IL-1 [21], as well as neuronal expression of both ApoE and $\beta$ APP [35]. The ability of IL- $1 \beta$ to induce $\beta$ APP expression $[30,42]$ raises the question of whether this is a direct mechanism or an indirect phenomenon resulting from ApoE induction, similar to the effect of glutamate [35]. In view of the relations between the AD-related stressors and the importance of ApoE in risk for development of $\mathrm{AD}$, together with the neuropathological changes observed in AD patients, we tested the hypothesis that ApoE would be elevated in CNS neurons secondary to several AD-related stressors associated with excessive expression of IL-1. Specifically, rat primary cortical neurons and a neuropotent human cell line (NTera2) were assessed for ApoE expression after treatment with IL- $1 \beta$, sAPP, glutamate, or $A \beta$. To delineate the roles of multi-lineage kinase (MLK) pathways in the induction of neuronal ApoE expression, we utilized inhibitors of p38-MAPK, ERK, and JNK pathways. To determine if such changes in ApoE expression might be observed in vivo, and the potential relationship of such changes to other proteins that are induced by IL-1, we measured the expression of ApoE, $\beta$ APP, and other neuroinflammatory proteins in rat brains exposed to excess IL-1 $\beta$.

\section{Materials and methods Pellet Implantation}

Pellets $(1.5 \mathrm{~mm}$ in diameter, designed for controlled slow release of compounds over a 21-day period; Innovative Research of America, Sarasota, FL) impregnated with IL-1 $\beta$ (100 ng recombinant mouse IL-1 $\beta$; Sigma Chemical Company, St. Louis, MO) and 'control' pellets (with bovine serum albumin) were implanted $2.8 \mathrm{~mm}$ caudal to bregma, $4.5 \mathrm{~mm}$ right of the midline, and 2.5 $\mathrm{mm}$ below the pial surface. Twenty-one male Sprague- 
Dawley rats, weighing $264 \pm 6$ g, were randomly assigned to three groups. Eight rats received implants of 21 -day timed-release IL-1 $\beta$-containing pellets, seven rats received sham (vehicle) pellets, and six rats served as unoperated controls. Twenty-one days after implantation, cortices from left hemispheres were collected for protein and mRNA isolation. For histological study, brain tissues were fixed in $10 \%$ formalin, embedded in paraffin, sectioned at $7 \mu \mathrm{m}$, and prepared for immunohistochemical analysis. All animal studies were conducted in accordance with a protocol reviewed and approved by the Institutional Animal Care and Use Committee of the Central Arkansas Veterans Healthcare System.

\section{Reagents}

Rat recombinant mature IL-1 $\beta$ (IL-1 $\beta$ holoprotein cleavage product) was purchased from Sigma (St. Louis MO), secreted APP (sAPP) was purified from a recombinant expression system as described previously [42], and L-glutamate was from Sigma (St. Louis MO). A $\beta_{1-42}$, from US Peptide Inc. (Rancho Cucamonga CA), was dissolved in DMSO and then incubated at $4{ }^{\circ} \mathrm{C}$ overnight prior to use. Rabbit anti-mouse IL- $1 \beta$ antibody was from Chemicon (Temecula CA); goat anti-human apolipoprotein $\mathrm{E}$ was from Calbiochem (Sunnyvale CA). Inhibitors of the p38-MAPK (SB203580), ERK (U0126), and JNK (SP600125) pathways were from Calbiochem. Medium, serum, and B27 supplement for cell cultures were from Invitrogen/Life Technologies (Grand Island NY). The antibodies used were rabbit anti-human IL-1 $\alpha$ (Peprotech 4:1000), goat anti-human APP (ADI 1:50), goat anti-Human APO E (Invitrogen 1:50), diluted in antibody diluent (Dako, Carpiteria CA).

\section{Immunofluorescence}

For immunofluorescent analysis of brain tissues, paraffin blocks were sectioned at $7 \mu \mathrm{m}$ and placed on precleaned microscope slides (Fischer). Then, sections were deparaffinized in xylene, rehydrated in graduated ethanol solutions to deionized water. For IL-1 $\alpha$ immunoreactions, sections were placed in boiling sodium citrate buffer (0.01 M, pH 6.0) for 20 minutes. Sections for $\beta \mathrm{APP}$ and ApoE were placed in trypsin solution for 10 minutes at $37^{\circ} \mathrm{C}$, all sections were blocked using protein block (Dako). For each antibody, sections were incubated overnight at room temperature. The secondary antibodies, Alexa Fluor donkey anti-goat and donkey anti-rabbit were diluted in antibody diluent (Dako) and sections were incubated for 60 minutes. The sections were then washed in three changes 5 minutes each of distilled $\mathrm{H}_{2} \mathrm{O}$ and then coverslipped with prolong Gold with DAPI (Invitrogen).

\section{Image Analysis}

Similar to our previous study [35], a quantitative approach was used to examine mean intensities of immunoreactions. Three representative images per slide (40× magnification) from IL-1-pellet, sham, and unoperated rat brains were obtained at identical exposure settings, using a Nikon Eclipse E600 microscope equipped with a Coolsnap monochrome camera. Each of the three images in each tissue section spanned a total area of $37241.5 \mu \mathrm{m}^{2}$. These images were from hippocampal CA1 and two cortical regions, one at the midline and another at the superior aspects of the temporal cortex and were acquired and analyzed using NIS-Elements BR3 software (Nikon.com). All cells of a type were captured, and images were thresholded. Data obtained from cells in each of the three regions were averaged, thus providing a single value for each image, and this value was used for statistical analysis. Data were analyzed by ANOVA to assess difference among groups. A statistical value of $\mathrm{p} \leq 0.05$ was defined as being significant.

\section{Cell Cultures}

Primary neuronal cultures were derived from cerebral cortex of fetal Spraque-Dawley rats (embryonic day 18), as previously described [43]. Experiments using primary neuronal cell cultures were performed after 10-14 days in culture. Highly purified cultures of rat microglia and astrocytes were generated from the cortical tissue of neonatal (0-3 days) Sprague-Dawley rats, as described previously $[43,44]$. The NTera2 human cell line (Stratagene, La Jolla, CA) was maintained in Dulbecco's modified Eagle medium (DMEM; Invitrogen/Life Technologies, Grand Island, NY) supplemented to $10 \%$ with fetal bovine serum (FBS). For specific experiments, SB203580 (5 $\mu \mathrm{M})$, U0126 $(5 \mu \mathrm{M})$, or SP600125 $(5 \mu \mathrm{M})$ was applied to cultures one hour before application of a stimulus. Glutamate released in the culture medium was assayed with a kit that utilizes a glutamate dehydrogenase-coupled color reaction (Roche Diagnostics, Indianapolis IN).

\section{Reverse Transcription (RT) Reaction and Polymerase Chain Reaction (PCR) Amplification}

Total RNA was extracted from cultured cells using TriReagent ${ }^{\mathrm{TM}}$ RNA (Molecular Research Center Inc., Cincinnati $\mathrm{OH}$ ) according to the manufacturer's instructions. Gel-based RT-PCR was performed as described previously [45]. Briefly, RT reactions were performed simultaneously using reagents from a single master mix, and PCR was performed using reagents from Clontech (Palo Alto CA). Aliquots of the product were resolved on agarose gels, ethidium bromide staining was captured by digital camera, and pixel intensities were quantified with Scion Image 4.0.3.2. Conditions were established to 
Table 1 RT-PCR primers

\begin{tabular}{|c|c|c|c|}
\hline Gene & Sequences & $\begin{array}{l}\text { Annealing } \\
\text { temp. }\left({ }^{\circ} \mathrm{C}\right)\end{array}$ & $\begin{array}{c}\text { Cycle } \\
\text { no. }\end{array}$ \\
\hline \multicolumn{4}{|c|}{ Gel-based PCR, rat } \\
\hline \multirow[t]{2}{*}{ ApoE } & $\begin{array}{l}\text { F: TGT TGG TCC CAT TGC TGA CAG } \\
\text { GAT }\end{array}$ & 60 & 25 \\
\hline & $\begin{array}{l}\text { R: TGG TGT TTA CCT CGT TGC GGT } \\
\text { ACT }\end{array}$ & & \\
\hline \multirow[t]{2}{*}{$\overline{\beta A P P}$} & F: CCC TGA CGC AGT CGA CAA GT & 61 & 25 \\
\hline & R: TGT CAT AAC CTG GGA CCG GAT & & \\
\hline \multirow[t]{2}{*}{ GAPDH } & F: CAA CGG ATT TGG CCG TAT TG & 61 & 25 \\
\hline & R: TGG GGG TAG GAA CAC GGA A & & \\
\hline \multirow[t]{2}{*}{$\overline{\mathrm{ICE}}$} & F: ACA AAG AAG GTG GCG CAT TTC & 61 & 28 \\
\hline & R: CCT TGT TTC TCT CCA CGG C & & \\
\hline \multirow[t]{2}{*}{$\mid \mathrm{IL}-1 \alpha$} & F: GAG TCA ACT CAT TGG CGC TTG & 60 & 27 \\
\hline & R: GGG CTG ATT GAA ACT TAG CCG & & \\
\hline \multirow[t]{2}{*}{ 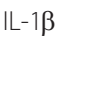 } & F: TGA CTC GTG GGA TGA TGA CG & 61 & 27 \\
\hline & R: CTG GAG ACT GCC CAT TCT CG & & \\
\hline \multirow[t]{2}{*}{ TNF } & F: GCA CAG AAA GCA TGA TCC GAG & 64 & 28 \\
\hline & R: CCT GGT ATG AAG TGG CAA ATC G & & \\
\hline \multicolumn{4}{|c|}{ Gel-based PCR, human } \\
\hline \multirow[t]{2}{*}{$\overline{\text { ApoE }}$} & F: TTC TGT GGG CTG CGT TGC TG & 60 & 25 \\
\hline & R: TAC ACT GCC AGG CGC TTC TG & & \\
\hline \multirow[t]{2}{*}{ GAPDH } & F: AGG TCG GAG TCA ACG GAT TTG & 61 & 25 \\
\hline & R: TGG CAG GTT TाT CTA GAC GGC & & \\
\hline \multicolumn{4}{|c|}{ Real-time PCR (rat) } \\
\hline \multirow[t]{2}{*}{$\overline{\mathrm{ApoE}}$} & F: CTG GTT CGA GCC GCT AGT G & 60 & N.A. \\
\hline & $\begin{array}{l}\text { R: CCT GTA TCT TCT CCA TTA GGT TTG } \\
\text { C }\end{array}$ & & \\
\hline \multirow[t]{2}{*}{$18 \mathrm{~S}$} & F: TTC GAA CGT CTG CCC TAT CAA & 60 & N.A. \\
\hline & R: ATG GTA GGC ACG GCG ACT A & & \\
\hline
\end{tabular}

ensure that maximal cycle number fell within the linear phase of amplification. Real-time (quantitative) RT-PCR was performed as described previously [35]. RT utilized random hexamers for priming, and PCR was performed with the Power SYBR-Green PCR Master Mix in an ABI 7900 HT Fast Real-time PCR System (Applied Biosystems, Foster City, CA). Signals were interpolated within standard curve reactions performed for each primer set, and the result for ApoE was expressed as a fraction of the $18 \mathrm{~S}$ signal for each sample. All primer sequences, annealing temperatures, and number of cycles are provided in Table 1.

\section{Western Immunoblot Assay}

Cellular fractions were prepared by application of a lysis buffer (50 mM Tris- $\mathrm{HCl}, \mathrm{pH} 7.5,150 \mathrm{mM} \mathrm{NaCl}, 1 \%$ Nonidet P40, 0.5\% sodium deoxycholate and 0.1\% SDS) to the cultures after a wash with cold PBS. Tissue samples were prepared by homogenization in RIPA buffer
(Cell Bioscience) as described previously [35,42]. Lysates were quantified using a Micro BCA assay reagent kit (Pierce, Rockford IL) as described previously [43]. Aliquots (100 $\mu \mathrm{g}$ each) were resolved by SDS-PAGE, subjected to electrophoresis at $70 \mathrm{~V}$ for 20 minutes and 90 $\mathrm{V}$ for $1.5 \mathrm{~h}$, and transferred to nitrocellulose membranes. After transfer, each blot was stained with Ponceau $S$ to ensure even loading of protein across lanes. Blots were then blocked in I-Block Buffer (Applied Biosystem Inc., Bedford, MA) for 45 minutes, then incubated overnight at $4{ }^{\circ} \mathrm{C}$ with goat anti-human ApoE (1:2000) primary antibody, incubated for $1 \mathrm{~h}$ at room temperature with alkaline phosphatase-conjugated secondary antibody, and developed using the WesternLight ${ }^{\mathrm{TM}}$ Chemiluminescent Detection System (Applied Biosystem Inc) and exposure to $x$-ray film. Digital images were captured and analyzed using NIH Image software, version 1.60 .

\section{Statistical Analysis}

Comparisons between two conditions were made via unpaired $t$-test, and experiments with a greater number of variables were subjected to ANOVA with Fisher's post hoc test. Differences were considered significant at $p$-values $\leq 0.05$.

\section{Results}

Chronic IL-1 $\beta$ increases the expression of ApoE, $\beta$ APP, and neuroinflammatory factors in rat brain

Rats were implanted with either slow-release (21-day) IL-1 $\beta$-impregnated pellets or vehicle-impregnated sham pellets. Cerebral cortices from these rats, as well as unoperated control rats, were processed for protein or mRNA tissue level analyses or were fixed and processed for immunofluorescent image analyses. Rat brains implanted with IL-1 $\beta$-containing pellets had markedly elevated steady-state levels of ApoE mRNA (Figure 1A, B) and of ApoE protein (Figure 1C,D) compared to those in rats implanted with sham pellets or to unoperated controls $(p<0.01)$.

Neuroinflammatory conditions and models thereof often exhibit chain reactions of multiple effectors working sequentially, in parallel, or in feedback loops fomenting a persistent and progressive situation. In this vein, the ability of IL-1 $\beta$ to elevate the levels of IL- $\alpha$ prompted an examination of gene-expression indices of neuroinflammation in this chronic IL- $1 \beta$ delivery paradigm. The increase in IL-1 $\alpha$ immunofluorescence noted above was found to be reflected at the mRNA level (Figure 2). Chronic IL-1 $\beta$ also elevated mRNA levels of endogenous IL-1 $\beta$, as well as its cleavage enzyme ICE (Figure 2). Along with these changes in IL-1-related molecules, the mRNA for the proinflammatory cytokine 
A

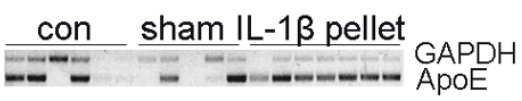

B

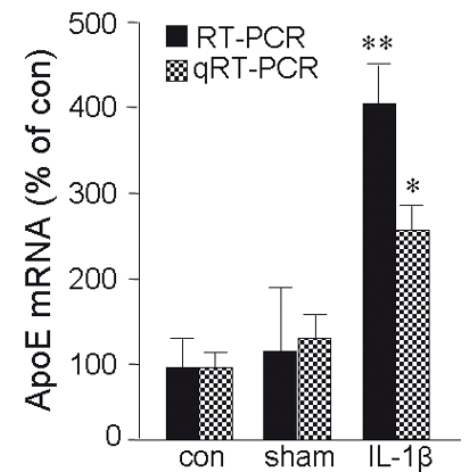

C

con sham IL-1 $1 \beta$ pellet

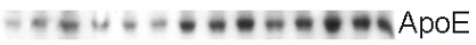

D

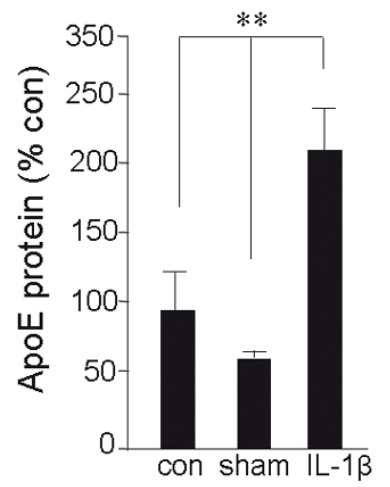

Figure $1 \mathrm{IL}-1 \beta$ induces ApoE expression in vivo. Proteins were extracted from the left cerebral cortex of unoperated rats (con), of rats implanted in the right cerebrum with a pellet containing vehicle alone (sham), and of rats implanted in the right cerebrum with a slow-release pellet containing $100 \mathrm{ng}$ IL-1 $\beta$ (IL-1 $\beta$ pellet). A: RNA was extracted from the left cerebral cortex of con $(n=6)$, sham $(n=5)$, and IL-1 $\beta$ pellet $(n$ = 7) rats and subjected to gel-based RT-PCR for ApoE and GAPDH. B: Quantification of the ApoE mRNA (relative to that for GAPDH) by densitometry of the RT-PCR image or by quantitative (real-time) RT-PCR (qRT-PCR); values reflect the percent of control as mean \pm SEM. C: Proteins were extracted from con $(n=3)$, sham $(n=3)$, and IL-1 $\beta$ pellet $(n=8)$ rats and subjected to western immunoblot analysis for ApoE. D: Quantification of autoradiography; values reflect percent of control as mean \pm SEM. ${ }^{*} p \leq 0.05$; ${ }^{* *} p<0.01$ versus control.

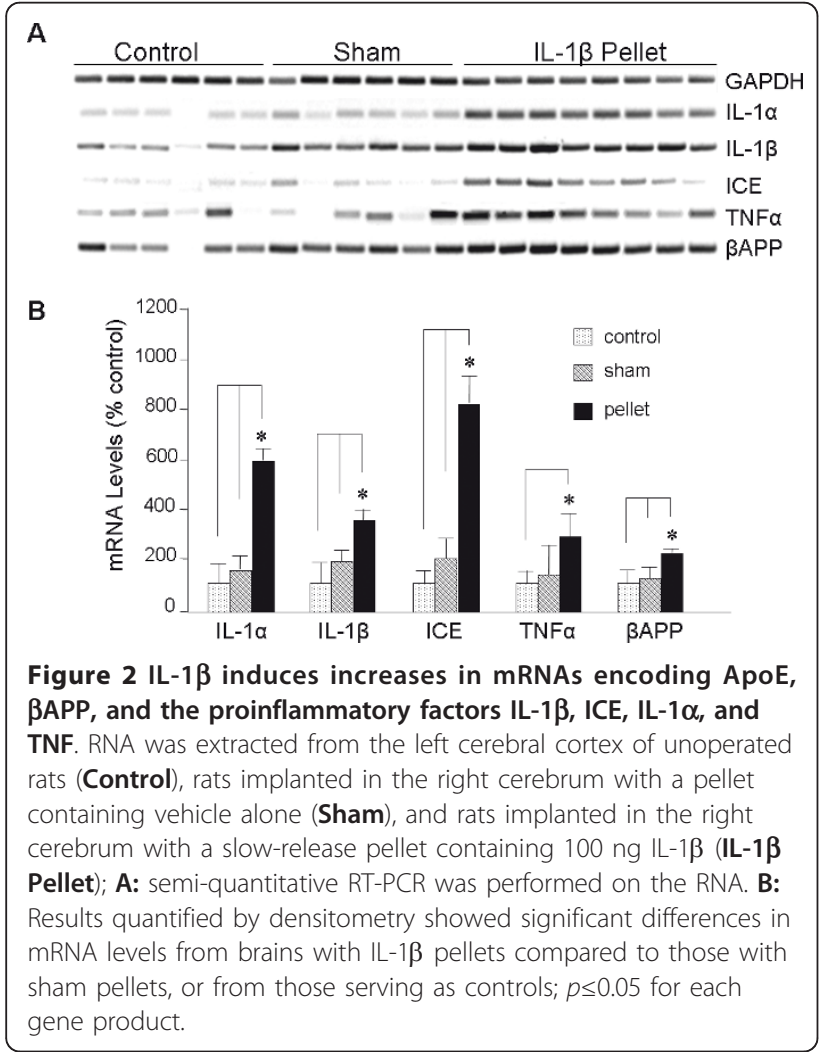

TNF was elevated. These proinflammatory changes were accompanied by induction of $\beta$ APP mRNA (Figure 2), consistent with the immunofluorescence results and prior studies of IL-1/ßAPP interactions.

The induction of ApoE in the cortex by IL- $1 \beta$ pellets was also detectable by immunofluorescence (Figure 3A), which demonstrated neuronal localization. IL- $1 \beta$ pellets also elevated expression of IL- $1 \alpha$ in the CA1 of hippocampus (Figure 3B). This IL-1 $\alpha$ induction was localized principally to cells with astrocytic morphology. Pyramidal neurons of the CA1 overexpressed $\beta$ APP in response to the chronic delivery of IL-1 $\beta$ (Figure 3C).

Tissue culture studies reveal potential for indirect impacts of IL-1 $\beta$ on ApoE

To examine the impact of IL- $1 \beta$ on ApoE expression in greater temporal and mechanistic detail, we utilized two types of neuronal cell culture: primary cultures of rat cortical neurons and the human NTera2 (NT2) cell line. We previously demonstrated that glutamate elevates $\beta$ APP expression via a mechanism that requires the biological activity of ApoE [35]. Moreover, IL-1 $\beta$ has been shown to influence the processing of $\beta$ APP [46]. Therefore, we tested whether ApoE expression was responsive to these agents and another derivative of $\beta A P P: A \beta_{1-42}$. In both culture types, expression of ApoE mRNA was elevated approximately two-fold by exposure to IL-1 $A \beta_{1-42}$, or glutamate for $20 \mathrm{~h}$; the induction by sAPP 


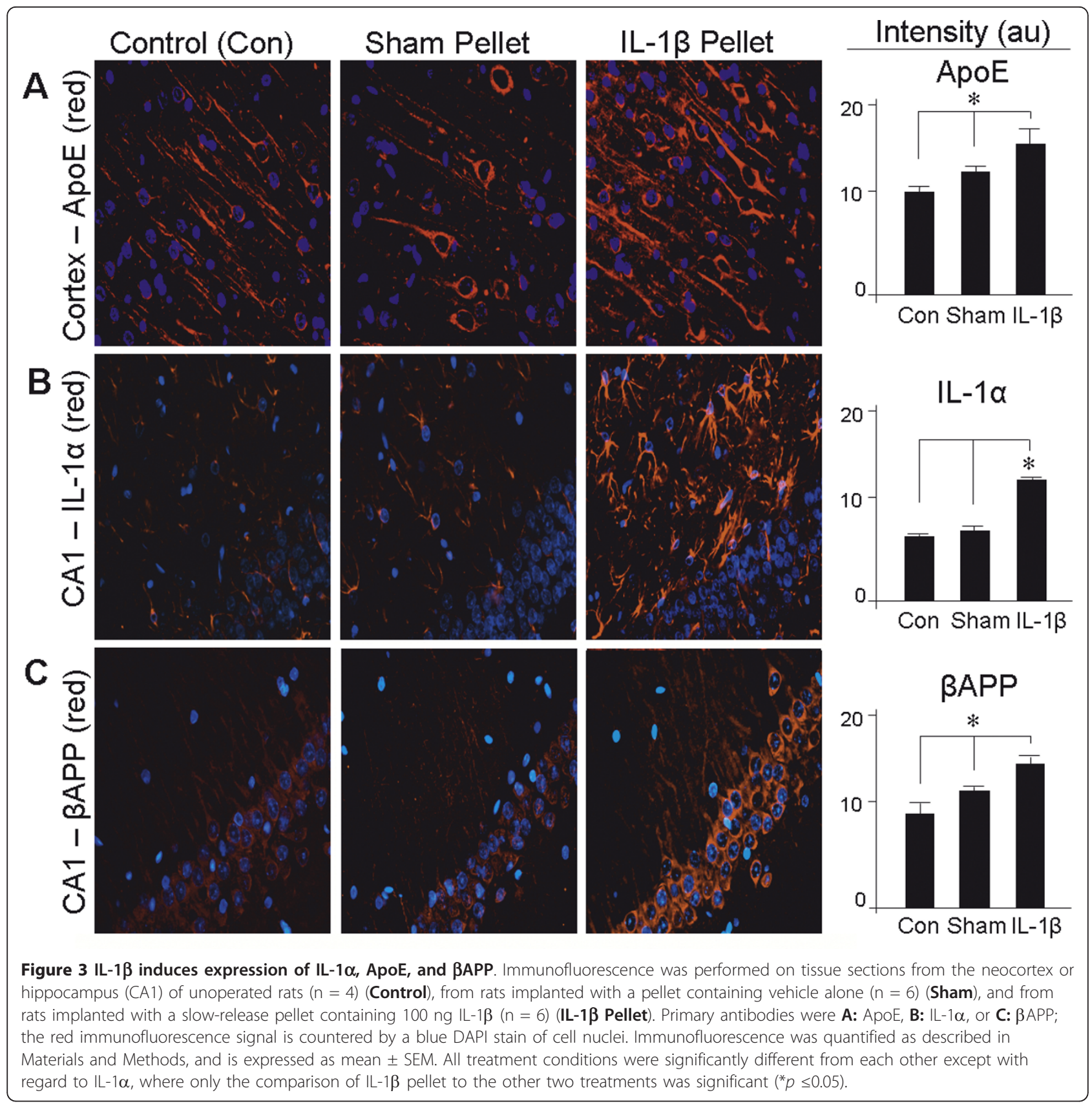

exceeded six-fold (Figure 4A). All of these agents were found to elevate ApoE protein levels as well (Figure 4B).

The ability of glutamate and $\beta$ APP fragments to impact ApoE was given additional relevance by demonstration of impacts of IL- $1 \beta$ on these agents. Levels of glutamate released into neuronal culture medium was elevated by IL-1 $\beta$ (Figure 5A). Likewise, IL-1 $\beta$ elevated the levels of sAPP in the culture medium of primary neurons in a dose-dependent fashion (Figure 5B). Glutamate induction of ApoE in primary neurons was confirmed by immunofluorescence, which also documented a larger induction by $A \beta_{1-42}$ (Figure $5 C, D$ ). Intriguingly, coapplication of glutamate in combination with $A \beta_{1-42}$ reduced the induction to one on par with that of glutamate alone (Figure 5D).

Regulation of ApoE expression by IL-1 $\beta, A \beta$, sAPP, and glutamate is via multi-lineage kinase pathways

Each of the IL-1 $\beta$-induced entities, SAPP and glutamate, as well as $A \beta$, were shown to elevate ApoE expression in both primary neurons and NT2 cells (Figure 5). To begin investigating the mechanisms involved in the 

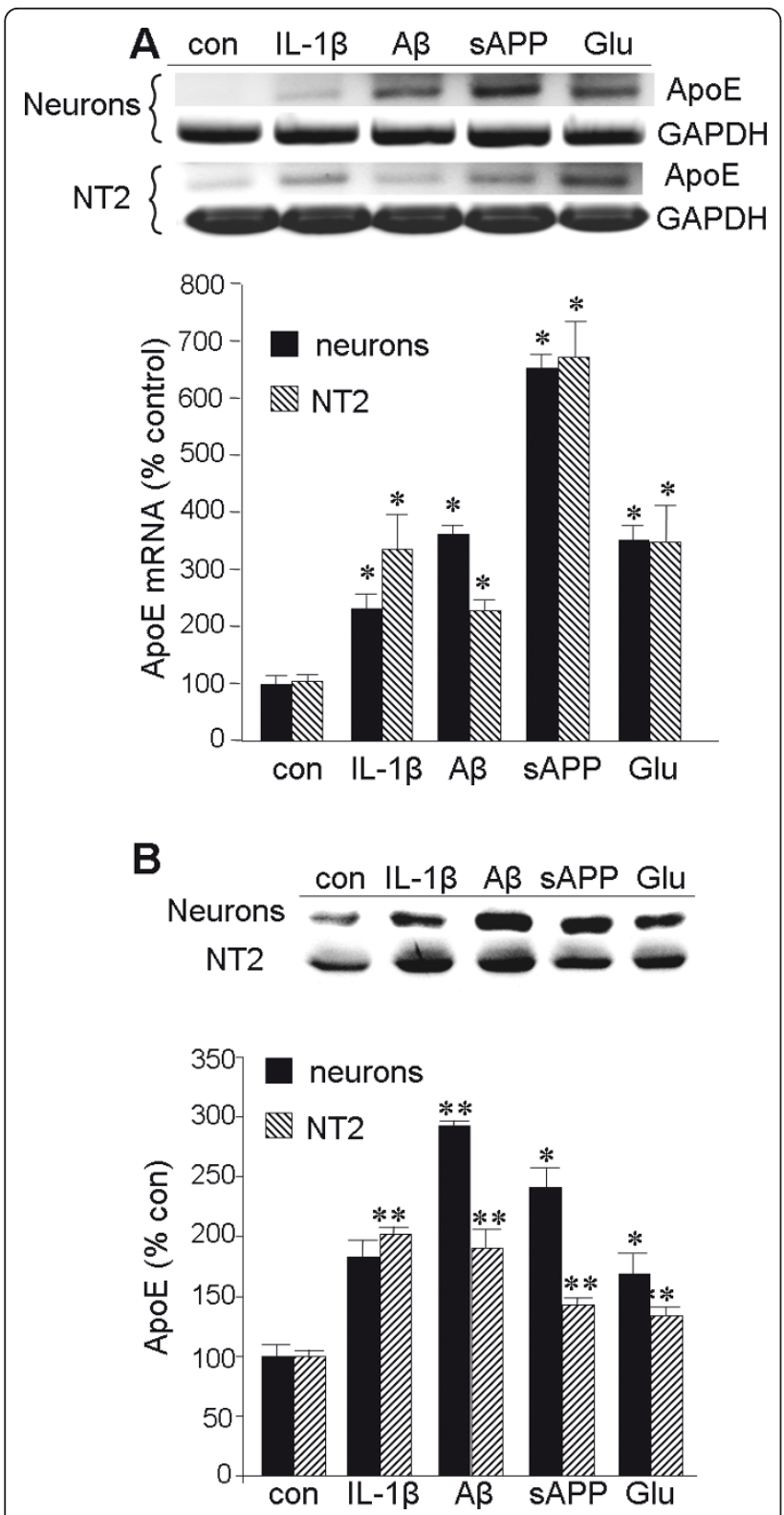

Figure 4 Elevation of ApoE expression in neuronal cells by stimuli relevant to Alzheimer's disease. Primary cortical neurons or NT2 cells were treated with $\mathrm{LL}-1 \beta(30 \mathrm{ng} / \mathrm{ml}), A \beta_{1-42}(10 \mu \mathrm{M})$, sAPP (30 nM), or Glu (50 $\mu \mathrm{M})$ for $20 \mathrm{~h}$. A: RNA was extracted from the cultures for RT-PCR of ApoE and GAPDH as illustrated. The results were quantified by densitometry, and values represent the mean \pm SEM for the ApoE amplimer relative to that for GAPDH. B: Cell lysates from the cultures were equilibrated for total protein levels and analyzed for ApoE content by western blot, also quantified by densitometry $\left({ }^{*} p<0.05,{ }^{* *} p<0.01\right)$.

induction of such ApoE expression, we focused on multi-lineage kinases (MLKs) previously shown to regulate cytokine-induced AD-related proteins [47]. Primary neurons and NT2 cells were incubated with inhibitors of three principle MLK pathways, viz., the MEK/ERK
(U0126), MAPK-p38 (SB203580), and JNK (SP600125) pathways. Constitutive expression of ApoE in both primary neurons and NT2 cells was unaffected by treatment with these inhibitors (data not shown). However, each of these MLK inhibitors suppressed induction of ApoE by IL-1 $\beta$ (Figure 6A), A $\beta_{1-42}$ (Figure 6B), and sAPP (Figure $6 \mathrm{C}$ ) in both types of culture. Induction of ApoE by glutamate in both NT2 and primary neurons was not inhibited by SB203580, a MAPK-p38 inhibitor. Thus, regulation of ApoE expression by MLK pathways appears to be somewhat selective and dependent on the effector of its induction; in the case of glutamate, ERK and JNK activity is involved but not MAPK-p38 (Figure 6D).

\section{Discussion}

The neuroinflammagenic potential of IL-1 $\beta$ is shown here through its induction of synthesis of itself and other proinflammatory cytokines including TNF, IL-1 $\alpha$, IL-1 $\beta$, as well as the latter's maturation enzyme ICE. The additional impact of IL- $1 \beta$ on neuronal ApoE production shown here suggests that in neurological conditions where the expression of proinflammatory cytokines is elevated, the expression of IL-1-driven ADrelated proteins such as ApoE would be elevated as well. Multiple MLKs-ERK, p38-MAPK, and JNK-were shown to be involved in elevated expression of ApoE in neurons exposed to IL-1 $\beta$, A $\beta$, or sAPP. The increased expression of ApoE induced by glutamate was mediated by ERK and JNK, but not by MAPK-p38. Together, these findings have several implications for AD pathogenesis, particularly with respect to conditions in which neuroinflammation is prominent, especially those influenced by $A P O E$ genotype.

The actions of IL-1 and the other agents tested heresAPP, A $\beta$, and glutamate-create the possibility for complex loops of influence analogous to the vicious circle of neuroinflammatory events we have termed the Cytokine Cycle [48]. Glutamate can elevate neuronal expression of $\beta$ APP and its conversion to sAPP [42]. $\beta$ APP is elevated in dystrophic neurites in and around plaques [49]; its breakdown into both SAPP and A $\beta$ can result in induction of IL-1 $\beta$ in microglia $[31,50]$. In addition to inducing IL-1 $\beta$ expression and release, sAPP and A $\beta$ also stimulate microglia to release biologically relevant levels of glutamate and its cooperative excitatory amino acid D-serine $[44,51,52]$. Thus, future studies should address the potential for each of these agents to act indirectly through the elaboration of a key agent or agents that can directly stimulate ApoE expression.

Key to interpretation of our findings-and, indeed, to the role of $A P O E$ genotype in $\mathrm{AD}$-is determining whether elevation of ApoE levels would be beneficial or harmful. Possession of the $\varepsilon 4$ allele is associated with enhanced deposition of $\mathrm{A} \beta$ [53], consistent with in vitro 


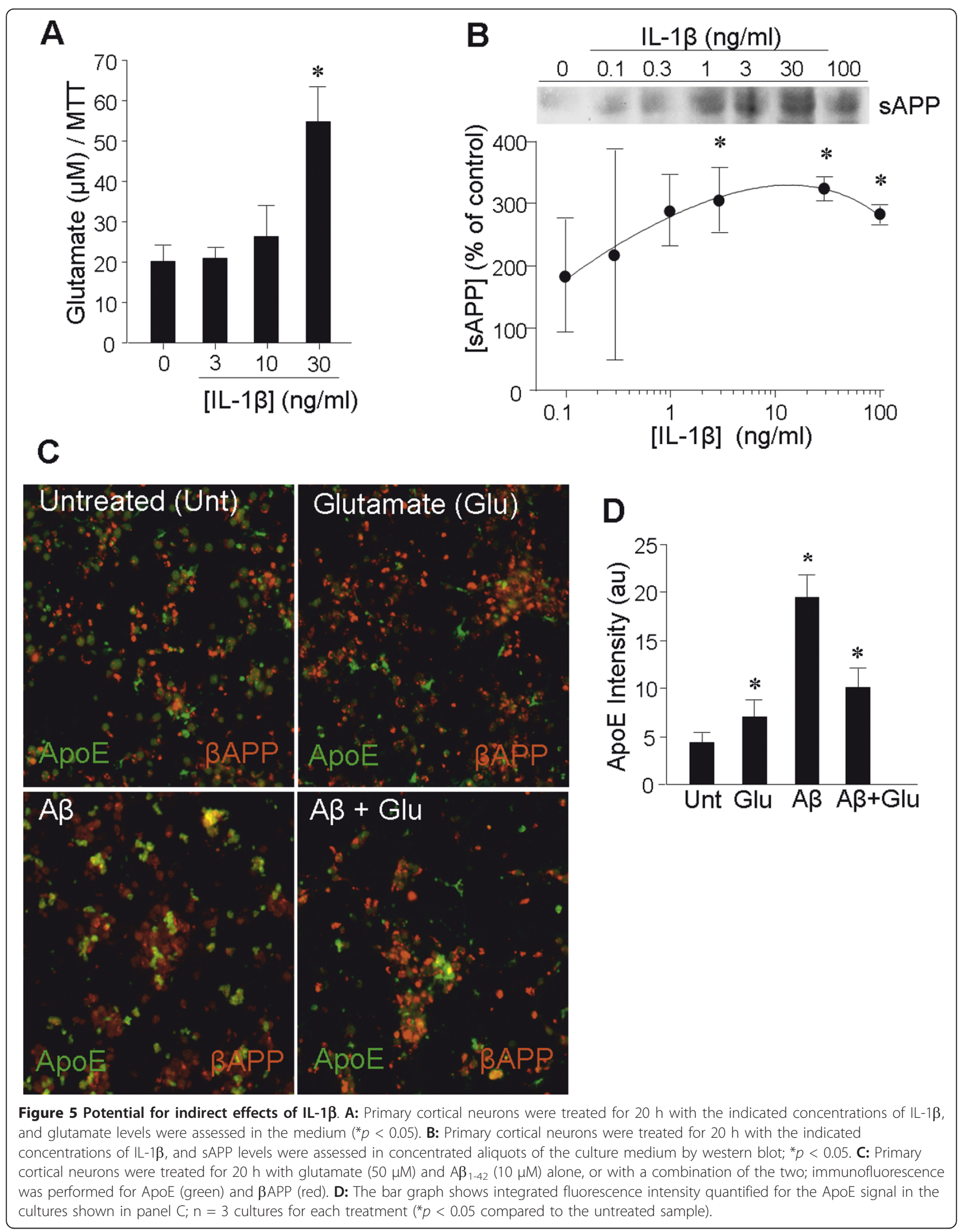




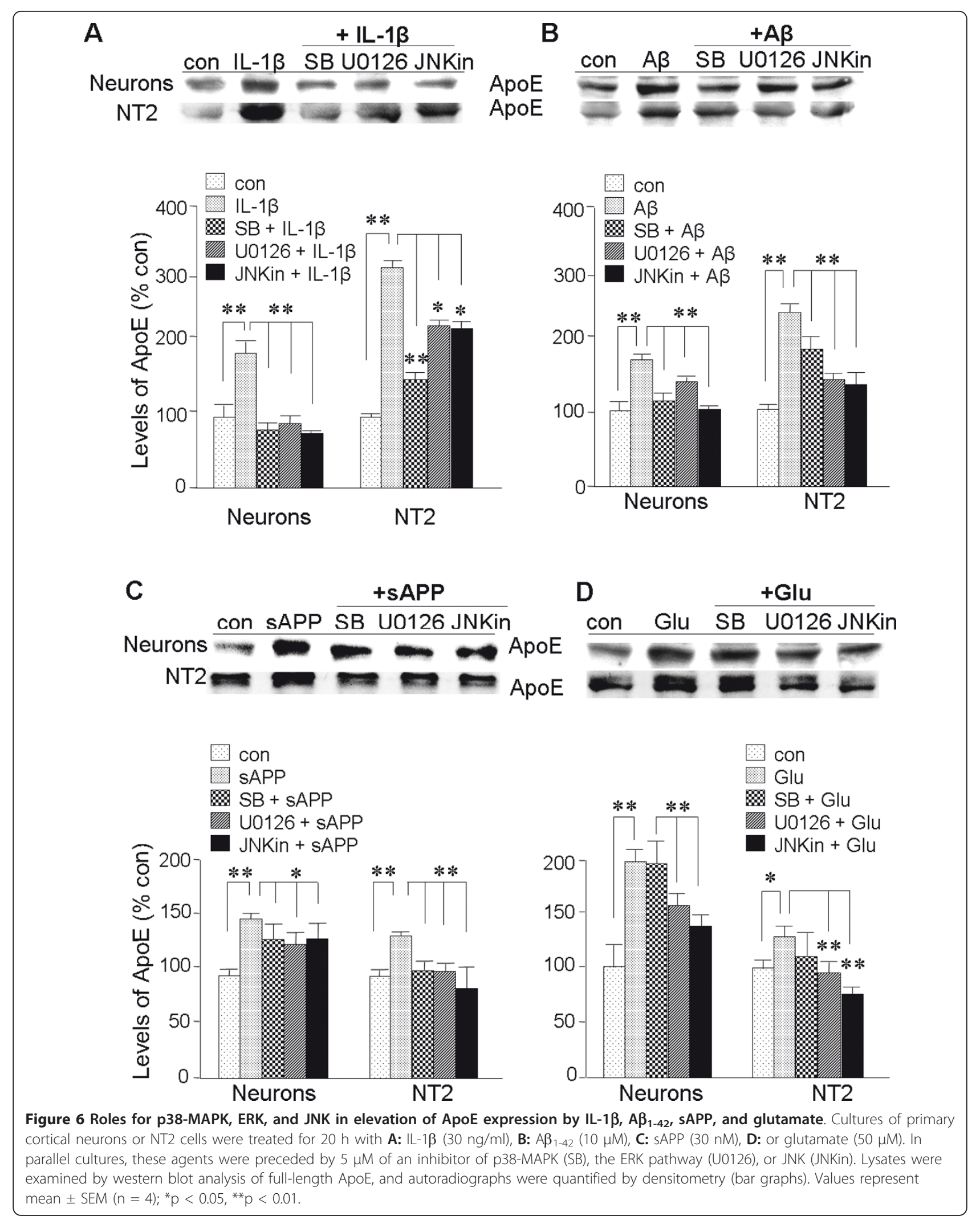


studies wherein $A p o E$ was shown to enhance $A \beta$ fibrillogenesis [54]. In this regard, ApoE4 has been shown to be more effective than ApoE3, fostering speculation that replacement of the $\varepsilon 3$ allele by $\varepsilon 4$ merely enhances an activity already present in ApoE3. This has been described as a toxic gain of function, implying that overabundance of any ApoE-even ApoE2 or ApoE3-would also create a gain in this function and thus be detrimental. Moreover, transient increases in cellular ApoE occur in response to injuries that promote $\mathrm{AD}$, e.g., traumatic brain injury [55] and stroke [56]. ApoE4 is generally reported to be present at higher steady-state levels than ApoE3 in CSF or brain parenchyma [57-61], though some studies have reported lower levels of total ApoE in $\varepsilon 4$-positive individuals $[62,63]$.

In contrast to these connections to pathology, ApoE provides neuroprotection in many paradigms, and ApoE deficiency has proved detrimental in several respects [64]. Therefore, inductions of ApoE by the stimuli we tested may represent a compensatory response, meaning that the distinction between ApoE3 and ApoE4 represents loss of a beneficial function. ApoE has anti-inflammatory effects, and even its interaction with $A \beta$ can attenuate glial activation by the latter [65]. However, ApoE3 is more effective than ApoE4 as an anti-inflammatory agent $[31,65,66]$, so this putative compensatory response may be inadequate in 84 -positive individuals and thus allow more extensive propagation of the Cytokine Cycle. Such an allele-specific compensatory response may also extend to direct neuroprotective activity. We previously reported that ApoE3 induces $\beta$ APP expression but ApoE4 does not [35], confirming the findings of Ezra et al. [67]. In this regard, elevations of ApoE by the process of neuroinflammation, or other stressors, would reflect a requisite role for the lipoprotein in enhancing the beneficial roles of $\beta$ APP and/or other acute-phase response proteins. Thus, it would be the inability of ApoE4 to participate in this chain of salutary events that makes it detrimental. We have previously shown that the increase in ApoE brain levels that occurs with aging continues to occur in $\mathrm{AD}$, with a large fraction being deposited in plaques [35]. This increase in ApoE levels is distinguishable from changes in $\beta$ APP, which rises with age but declines markedly in AD [35]. This disease-associated severance of the coordinate regulation of ApoE and $\beta$ APP further strengthens the correlation of brain health with the coregulation of these two proteins; to wit, with ApoE expression itself, provided that the ApoE is not ApoE4.

Multi-lineage kinase pathways may be invoked in the regulation of ApoE expression, and can themselves be invoked by ApoE $[68,69]$, suggesting a feedback loop between MLK pathways and ApoE expression in neurons. Our findings of involvement of multiple MLKs-
ERK, p38-MAPK, and JNK-in expression of ApoE in neurons exposed to IL-1 $\beta, A \beta$, or sAPP, together with previous reports of ERK pathway invocation of ApoE expression and vice versa, are consistent with the existence of a complex feedback system that may be important in acute-phase responses to neuronal injury as well as potential exacerbation of neurodegenerative events. Our finding that glutamate regulates ApoE expression via ERK and JNK, but not by $\mathrm{p} 38$-MAPK pathways may be indicative of a correlation between glutamatergic induction of ApoE and neuronal survival. Excitotoxic effects of glutamate are largely dependent upon activation of extrasynaptic NMDA receptors, p38-MAPK, and the inhibition of ERK signaling; synaptic receptors, on the other hand, appear to activate ERK and promote survival [70-72].

In conclusion, the induction of neuronal ApoE by either neuroinflammatory or excitotoxic agents or neurotoxins, acting through MLK pathways suggests that alterations in these signaling pathways, together with other neuropathological entities in AD brain, may have consequences for ApoE expression. Differences in this expression may be critical, considering the role of $A P O E$ genotype in $\mathrm{AD}$ risk. The response of ApoE to IL-1 $\beta$ we show here in rodent brain suggests that elevation of IL1 leads to the increases in ApoE that we and others have observed in the AD brain. This may have added significance with regard to the self-propagating nature of IL-1-driven cascades, especially when such cascades are instigated in the context of an $\varepsilon 4$ allele of $A P O E$. While induction of ApoE2 or ApoE3 may be antiinflammatory or neuroprotective, and thereby act as a self-limiting influence on IL-1-driven cascades, ApoE4 may fail to participate and leave the brain vulnerable to prolonged activation of a maladaptive cycle.

\section{Acknowledgements}

The authors thank John McGinness, Quinton Palmer, Dr. Jin G. Sheng, Sue Woodward, and Weiwen Ye for technical support. This work was supported in part by NIH grants AG12411, AG19606, HD37989, AG17498, and AG033215; by a grant from the Alzheimer's Association; and by endowments from The Alexa and William T. Dillard, the Windgate Foundation, and the Donald W. Reynolds Foundation.

\section{Author details}

Department of Geriatrics, University of Arkansas for Medical Sciences, Little Rock AR 72205, USA. ${ }^{2}$ Neurobiology and Developmental Sciences, University of Arkansas for Medical Sciences, Little Rock AR 72205, USA. ${ }^{3}$ Geriatric Research Education and Clinical Center, Central Arkansas Veterans Healthcare System, Little Rock AR 72205, USA. ${ }^{4}$ Department of Pathology, University of Toledo Health Science Campus, Toledo OH 43614, USA.

\section{Authors' contributions}

$\mathrm{LL}$ performed the cell culture experiments and contributed to writing the first draft of the manuscript. OA performed the immunofluorescence and assisted with western blots and writing. RAJ performed the experiments with rat brain tissue. REM contributed to interpretation of the results and to writing. WSTG contributed to the design of the study, interpretation of the results, and writing. SWB made essential contributions to the design of the 
study and interpretation of the results and completed the final draft of the manuscript. All authors read and approved the final manuscript.

\section{Competing interests}

S.W.B. receives royalty payments from Sigma-Aldrich Corp., which manufactures some of the reagents utilized in this study. The authors have no other conflicts to declare.

Received: 21 June 2011 Accepted: 15 December 2011

Published: 15 December 2011

\section{References}

1. Blackman JA, Worley G, Strittmatter WJ: Apolipoprotein E and brain injury: implications for children. Dev Med Child Neurol 2005, 47:64-70.

2. D'Arcangelo G: Apoer2: a reelin receptor to remember. Neuron 2005 47:471-473.

3. D'Arcangelo G, Homayouni R, Keshvara L, Rice DS, Sheldon M, Curran T: Reelin is a ligand for lipoprotein receptors. Neuron 1999, 24:471-479.

4. Strittmatter WJ, Bova Hill C: Molecular biology of apolipoprotein E. Curr Opin Lipidol 2002, 13:119-123.

5. Strittmatter WJ, Saunders AM, Goedert M, Weisgraber KH, Dong LM, Jakes R, Huang DY, Pericak-Vance M, Schmechel D, Roses AD: Isoform-specific interactions of apolipoprotein $\mathrm{E}$ with microtubule-associated protein tau: implications for Alzheimer disease. Proc Natl Acad Sci USA 1994, 91:11183-11186.

6. $\mathrm{Bu}$ G: Apolipoprotein $\mathrm{E}$ and its receptors in Alzheimer's disease: pathways, pathogenesis and therapy. Nat Rev Neurosci 2009.

7. Boschert U, Merlo-Pich E, Higgins G, Roses AD, Catsicas S: Apolipoprotein E expression by neurons surviving excitotoxic stress. Neurobiol Dis 1999 6:508-514

8. Xu Q, Bernardo A, Walker D, Kanegawa T, Mahley RW, Huang Y: Profile and regulation of apolipoprotein $E$ (ApoE) expression in the CNS in mice with targeting of green fluorescent protein gene to the ApoE locus. J Neurosci 2006, 26:4985-4994.

9. Du Y, Dodel RC, Eastwood BJ, Bales KR, Gao F, Lohmuller F, Muller U, Kurz A, Zimmer R, Evans RM, et al: Association of an interleukin 1 alpha polymorphism with Alzheimer's disease. Neurology 2000, 55:480-483.

10. Grimaldi LM, Casadei VM, Ferri C, Veglia F, Licastro F, Annoni G, Biunno I, De Bellis G, Sorbi S, Mariani C, et al: Association of early-onset Alzheimer's disease with an interleukin-1alpha gene polymorphism. Ann Neurol 2000, 47:361-365.

11. Nicoll JA, Mrak RE, Graham DI, Stewart J, Wilcock G, MacGowan S, Esiri MM, Murray LS, Dewar D, Love $S$, et al: Association of interleukin-1 gene polymorphisms with Alzheimer's disease. Ann Neurol 2000, 47:365-368.

12. Rebeck GW: Confirmation of the genetic association of interleukin-1A with early onset sporadic Alzheimer's disease. Neurosci Lett 2000, 293:75-77.

13. Bertram L, Tanzi RE: Thirty years of Alzheimer's disease genetics: the implications of systematic meta-analyses. Nat Rev Neurosci 2008 9:768-778

14. Griffin WS, Sheng JG, Gentleman SM, Graham DI, Mrak RE, Roberts GW: Microglial interleukin-1 alpha expression in human head injury: correlations with neuronal and neuritic beta-amyloid precursor protein expression. Neurosci Lett 1994, 176:133-136.

15. Stanley LC, Mrak RE, Woody RC, Perrot LJ, Zhang S, Marshak DR, Nelson SJ, Griffin WS: Glial cytokines as neuropathogenic factors in HIV infection: pathogenic similarities to Alzheimer's disease. J Neuropathol Exp Neurol 1994, 53:231-238.

16. Sheng JG, Boop FA, Mrak RE, Griffin WS: Increased neuronal beta-amyloid precursor protein expression in human temporal lobe epilepsy: association with interleukin-1 alpha immunoreactivity. J Neurochem 1994 , 63:1872-1879.

17. Griffin WS, Yeralan O, Sheng JG, Boop FA, Mrak RE, Rovnaghi CR, Burnett BA, Feoktistova A, Van Eldik LJ: Overexpression of the neurotrophic cytokine $\mathrm{S} 100$ beta in human temporal lobe epilepsy. $J$ Neurochem 1995, 65:228-233.

18. Mackenzie IR, Miller LA: Senile plaques in temporal lobe epilepsy. Acta Neuropathol (Berl) 1994, 87:504-510.

19. Vezzani A, Balosso S, Ravizza T: The role of cytokines in the pathophysiology of epilepsy. Brain Behav Immun 2008, 22:797-803.
20. Griffin WS, Stanley LC, Ling C, White L, MacLeod V, Perrot $L$, White CL, Araoz C: Brain interleukin 1 and S-100 immunoreactivity are elevated in Down syndrome and Alzheimer disease. Proc Natl Acad Sci USA 1989, 86:7611-7615.

21. Sheng JG, Mrak RE, Griffin WS: Enlarged and phagocytic, but not primed, interleukin-1 alpha-immunoreactive microglia increase with age in normal human brain. Acta Neuropathol (Berl) 1998, 95:229-234.

22. Blasko I, Stampfer-Kountchev M, Robatscher P, Veerhuis R, Eikelenboom P, Grubeck-Loebenstein B: How chronic inflammation can affect the brain and support the development of Alzheimer's disease in old age: the role of microglia and astrocytes. Aging Cell 2004, 3:169-176.

23. Gee JR, Ding Q, Keller JN: Age-related alterations of Apolipoprotein E and interleukin-1beta in the aging brain. Biogerontology 2006, 7:69-79.

24. Esiri MM, Biddolph SC, Morris CS: Prevalence of Alzheimer plaques in AIDS. J Neurol Neurosurg Psychiatry 1998, 65:29-33.

25. Graham DI, Gentleman SM, Nicoll JA, Royston MC, McKenzie JE, Roberts GW, Griffin WS: Altered beta-APP metabolism after head injury and its relationship to the aetiology of Alzheimer's disease. Acta Neurochir Suppl 1996, 66:96-102.

26. Gouras GK, Relkin NR, Sweeney D, Munoz DG, Mackenzie IR, Gandy S: Increased apolipoprotein E epsilon 4 in epilepsy with senile plaques. Ann Neurol 1997, 41:402-404.

27. Teasdale GM, Murray GD, Nicoll JA: The association between APOE epsilon4, age and outcome after head injury: a prospective cohort study. Brain 2005, 128:2556-2561.

28. Corder EH, Robertson K, Lannfelt L, Bogdanovic N, Eggertsen G, Wilkins J, Hall C: HIV-infected subjects with the E4 allele for APOE have excess dementia and peripheral neuropathy. Nat Med 1998, 4:1182-1184.

29. Prasher VP, Farrer MJ, Kessling AM, Fisher EM, West RJ, Barber PC, Butler AC: Molecular mapping of Alzheimer-type dementia in Down's syndrome. Ann Neurol 1998, 43:380-383.

30. Sheng JG, Ito K, Skinner RD, Mrak RE, Rovnaghi CR, Van Eldik LJ, Griffin WS: In vivo and in vitro evidence supporting a role for the inflammatory cytokine interleukin-1 as a driving force in Alzheimer pathogenesis. Neurobiol Aging 1996, 17:761-766.

31. Barger SW, Harmon AD: Microglial activation by Alzheimer amyloid precursor protein and modulation by apolipoprotein E. Nature 1997, 388:878-881.

32. Sheng JG, Mrak RE, Griffin WS: Apolipoprotein E distribution among different plaque types in Alzheimer's disease: implications for its role in plaque progression. Neuropathol Appl Neurobiol 1996, 22:334-341.

33. Bales KR, Verina T, Cummins DJ, Du Y, Dodel RC, Saura J, Fishman CE, DeLong CA, Piccardo P, Petegnief $V$, et al: Apolipoprotein $E$ is essential for amyloid deposition in the APP(V717F) transgenic mouse model of Alzheimer's disease. Proc Natl Acad Sci USA 1999, 96:15233-15238.

34. Griffin WS, Liu L, Li Y, Mrak RE, Barger SW: Interleukin-1 mediates Alzheimer and Lewy body pathologies. J Neuroinflammation 2006, 3:5.

35. Barger SW, DeWall KM, Liu L, Mrak RE, Griffin WS: Relationships between expression of apolipoprotein $\mathrm{E}$ and beta-amyloid precursor protein are altered in proximity to Alzheimer beta-amyloid plaques: potential explanations from cell culture studies. J Neuropathol Exp Neurol 2008, 67:773-783.

36. Senechal Y, Kelly PH, Dev KK: Amyloid precursor protein knockout mice show age-dependent deficits in passive avoidance learning. Behav Brain Res 2008, 186:126-132.

37. Dawson GR, Seabrook GR, Zheng H, Smith DW, Graham S, O'Dowd G, Bowery BJ, Boyce S, Trumbauer ME, Chen HY, et al: Age-related cognitive deficits, impaired long-term potentiation and reduction in synaptic marker density in mice lacking the beta-amyloid precursor protein. Neuroscience 1999, 90:1-13.

38. Mattson MP: Cellular actions of beta-amyloid precursor protein and its soluble and fibrillogenic derivatives. Physiol Rev 1997, 77:1081-1132.

39. Laskowitz DT, Matthew WD, Bennett ER, Schmechel D, Herbstreith MH, Goel S, McMillian MK: Endogenous apolipoprotein E suppresses LPSstimulated microglial nitric oxide production. Neuroreport 1998, 9:615-618.

40. Lynch JR, Morgan D, Mance J, Matthew WD, Laskowitz DT: Apolipoprotein E modulates glial activation and the endogenous central nervous system inflammatory response. J Neuroimmunol 2001, 114:107-113.

41. Koistinaho M, Kettunen MI, Holtzman DM, Kauppinen RA, Higgins LS, Koistinaho J: Expression of human apolipoprotein E downregulates 
amyloid precursor protein-induced ischemic susceptibility. Stroke 2002, 33:1905-1910.

42. Li Y, Liu L, Kang J, Sheng JG, Barger SW, Mrak RE, Griffin WS: Neuronal-glial interactions mediated by interleukin-1 enhance neuronal acetylcholinesterase activity and mRNA expression. J Neurosci 2000, 20:149-155.

43. Li Y, Wang J, Sheng JG, Liu L, Barger SW, Jones RA, Van Eldik LJ, Mrak RE, Griffin WS: S100 beta increases levels of beta-amyloid precursor protein and its encoding mRNA in rat neuronal cultures. J Neurochem 1998, 71:1421-1428.

44. Wu SZ, Bodles AM, Porter MM, Griffin WS, Basile AS, Barger SW: Induction of serine racemase expression and D-serine release from microglia by amyloid beta-peptide. J Neuroinflammation 2004, 1:2.

45. Li Y, Liu L, Barger SW, Mrak RE, Griffin WS: Vitamin E suppression of microglial activation is neuroprotective. J Neurosci Res 2001, 66:163-170.

46. Buxbaum JD, Oishi M, Chen HI, Pinkas-Kramarski R, Jaffe EA, Gandy SE, Greengard P: Cholinergic agonists and interleukin 1 regulate processing and secretion of the Alzheimer beta/A4 amyloid protein precursor. Proc Natl Acad Sci USA 1992, 89:10075-10078.

47. Sheng JG, Jones RA, Zhou XQ, McGinness JM, Van Eldik LJ, Mrak RE, Griffin WS: Interleukin-1 promotion of MAPK-p38 overexpression in experimental animals and in Alzheimer's disease: potential significance for tau protein phosphorylation. Neurochem Int 2001, 39:341-348.

48. Griffin WS, Sheng JG, Royston MC, Gentleman SM, McKenzie JE, Graham DI, Roberts GW, Mrak RE: Glial-neuronal interactions in Alzheimer's disease: the potential role of a 'cytokine cycle' in disease progression. Brain Pathol 1998, 8:65-72.

49. Mrak RE, Sheng JG, Griffin WS: Correlation of astrocytic S100 beta expression with dystrophic neurites in amyloid plaques of Alzheimer's disease. J Neuropathol Exp Neurol 1996, 55:273-279.

50. Meda L, Baron P, Prat E, Scarpini E, Scarlato G, Cassatella MA, Rossi F: Proinflammatory profile of cytokine production by human monocytes and murine microglia stimulated with beta-amyloid[25-35]. J Neuroimmunol 1999, 93:45-52.

51. Barger SW, Mattson MP: Isoform-specific modulation by apolipoprotein E of the activities of secreted beta-amyloid precursor protein. J Neurochem 1997, 69:60-67.

52. Wu S, Basile AS, Barger SW: Induction of serine racemase expression and $D$-serine release from microglia by secreted amyloid precursor protein (SAPP). Curr Alzheimer Res 2007, 4:243-251.

53. Schmechel DE, Saunders AM, Strittmatter WJ, Crain BJ, Hulette CM, Joo SH, Pericak-Vance MA, Goldgaber D, Roses AD: Increased amyloid betapeptide deposition in cerebral cortex as a consequence of apolipoprotein E genotype in late-onset Alzheimer disease. Proc Natl Acad Sci USA 1993, 90:9649-9653.

54. Wisniewski T, Castano EM, Golabek A, Vogel T, Frangione B: Acceleration of Alzheimer's fibril formation by apolipoprotein $\mathrm{E}$ in vitro. Am J Pathol 1994, 145:1030-1035.

55. Horsburgh K, Fitzpatrick M, Nilsen M, Nicoll JA: Marked alterations in the cellular localisation and levels of apolipoprotein E following acute subdural haematoma in rat. Brain Res 1997, 763:103-110.

56. Kay A, Petzold A, Kerr M, Keir G, Thompson E, Nicoll J: Temporal alterations in cerebrospinal fluid amyloid beta-protein and apolipoprotein $\mathrm{E}$ after subarachnoid hemorrhage. Stroke 2003, 34:e240-243.

57. Lambert JC, Perez-Tur J, Dupire MJ, Galasko D, Mann D, Amouyel P, Hardy J, Delacourte A, Chartier-Harlin MC: Distortion of allelic expression of apolipoprotein E in Alzheimer's disease. Hum Mol Genet 1997, 6:2151-2154.

58. Hesse C, Larsson H, Fredman P, Minthon L, Andreasen N, Davidsson P, Blennow K: Measurement of apolipoprotein E (apoE) in cerebrospinal fluid. Neurochem Res 2000, 25:511-517.

59. Fukumoto H, Ingelsson M, Garevik N, Wahlund LO, Nukina N, Yaguchi Y, Shibata M, Hyman BT, Rebeck GW, Irizarry MC: APOE epsilon 3/epsilon 4 heterozygotes have an elevated proportion of apolipoprotein E4 in cerebrospinal fluid relative to plasma, independent of Alzheimer's disease diagnosis. Exp Neurol 2003, 183:249-253.

60. Bray NJ, Jehu L, Moskvina V, Buxbaum JD, Dracheva S, Haroutunian V, Williams J, Buckland PR, Owen MJ, O'Donovan MC: Allelic expression of APOE in human brain: effects of epsilon status and promoter haplotypes. Hum Mol Genet 2004, 13:2885-2892.
61. Darreh-Shori T, Modiri N, Blennow K, Baza S, Kamil C, Ahmed H, Andreasen $\mathrm{N}$, Nordberg A: The apolipoprotein E varepsilon4 allele plays pathological roles in $A D$ through high protein expression and interaction with butyrylcholinesterase. Neurobiol Aging 2009.

62. Beffert U, Cohn JS, Petit-Turcotte C, Tremblay M, Aumont N, Ramassamy C, Davignon J, Poirier J: Apolipoprotein E and beta-amyloid levels in the hippocampus and frontal cortex of Alzheimer's disease subjects are disease-related and apolipoprotein E genotype dependent. Brain Res 1999, 843:87-94.

63. Bertrand P, Poirier J, Oda T, Finch CE, Pasinetti GM: Association of apolipoprotein $\mathrm{E}$ genotype with brain levels of apolipoprotein $\mathrm{E}$ and apolipoprotein J (clusterin) in Alzheimer disease. Brain Res Mol Brain Res 1995, 33:174-178.

64. Kim J, Basak JM, Holtzman DM: The role of apolipoprotein E in Alzheimer's disease. Neuron 2009, 63:287-303.

65. Guo L, LaDu MJ, Van Eldik LJ: A dual role for apolipoprotein e in neuroinflammation: anti- and pro-inflammatory activity. J Mol Neurosci 2004, 23:205-212.

66. Colton CA, Brown CM, Cook D, Needham LK, Xu Q, Czapiga M, Saunders AM, Schmechel DE, Rasheed K, Vitek MP: APOE and the regulation of microglial nitric oxide production: a link between genetic risk and oxidative stress. Neurobiol Aging 2002, 23:777-785.

67. Ezra Y, Oron L, Moskovich L, Roses AD, Beni SM, Shohami E, Michaelson DM: Apolipoprotein E4 decreases whereas apolipoprotein E3 increases the level of secreted amyloid precursor protein after closed head injury. Neuroscience 2003, 121:315-325.

68. Hoe HS, Harris DC, Rebeck GW: Multiple pathways of apolipoprotein E signaling in primary neurons. J Neurochem 2005, 93:145-155.

69. Ohkubo N, Mitsuda N, Tamatani M, Yamaguchi A, Lee YD, Ogihara T, Vitek MP, Tohyama M: Apolipoprotein E4 stimulates CAMP response element-binding protein transcriptional activity through the extracellular signal-regulated kinase pathway. J Biol Chem 2001, 276:3046-3053.

70. Hardingham GE, Fukunaga Y, Bading H: Extrasynaptic NMDARs oppose synaptic NMDARs by triggering CREB shut-off and cell death pathways. Nat Neurosci 2002, 5:405-414

71. Soriano FX, Martel MA, Papadia S, Vaslin A, Baxter P, Rickman C, Forder J, Tymianski M, Duncan R, Aarts M, et al: Specific targeting of pro-death NMDA receptor signals with differing reliance on the NR2B PDZ ligand. J Neurosci 2008, 28:10696-10710.

72. Xu J, Kurup P, Zhang Y, Goebel-Goody SM, Wu PH, Hawasli AH, Baum ML, Bibb JA, Lombroso PJ: Extrasynaptic NMDA receptors couple preferentially to excitotoxicity via calpain-mediated cleavage of STEP. J Neurosci 2009, 29:9330-9343.

doi:10.1186/1742-2094-8-175

Cite this article as: Liu et al:: Apolipoprotein E expression is elevated by interleukin 1 and other interleukin 1-induced factors. Journal of Neuroinflammation 2011 8:175.

\section{Submit your next manuscript to BioMed Central and take full advantage of:}

- Convenient online submission

- Thorough peer review

- No space constraints or color figure charges

- Immediate publication on acceptance

- Inclusion in PubMed, CAS, Scopus and Google Scholar

- Research which is freely available for redistribution

Submit your manuscript at www.biomedcentral.com/submit
C Biomed Central 